\title{
Microporous calcium phosphate ceramics driving osteogenesis through surface architecture
}

Citation for published version (APA):

Zhang, J., Barbieri, D., ten Hoopen, H., de Bruijn, J. D., van Blitterswijk, C. A., \& Yuan, H. (2015).

Microporous calcium phosphate ceramics driving osteogenesis through surface architecture. Journal of Biomedical Materials Research Part A, 103(3), 1188-1199. https://doi.org/10.1002/jbm.a.35272

Document status and date:

Published: 01/03/2015

DOI:

10.1002/jbm.a.35272

Document Version:

Publisher's PDF, also known as Version of record

Document license:

Taverne

Please check the document version of this publication:

- A submitted manuscript is the version of the article upon submission and before peer-review. There can be important differences between the submitted version and the official published version of record.

People interested in the research are advised to contact the author for the final version of the publication, or visit the DOI to the publisher's website.

- The final author version and the galley proof are versions of the publication after peer review.

- The final published version features the final layout of the paper including the volume, issue and page numbers.

Link to publication

\footnotetext{
General rights rights.

- You may freely distribute the URL identifying the publication in the public portal. please follow below link for the End User Agreement:

www.umlib.nl/taverne-license

Take down policy

If you believe that this document breaches copyright please contact us at:

repository@maastrichtuniversity.nl

providing details and we will investigate your claim.
}

Copyright and moral rights for the publications made accessible in the public portal are retained by the authors and/or other copyright owners and it is a condition of accessing publications that users recognise and abide by the legal requirements associated with these

- Users may download and print one copy of any publication from the public portal for the purpose of private study or research.

- You may not further distribute the material or use it for any profit-making activity or commercial gain

If the publication is distributed under the terms of Article $25 \mathrm{fa}$ of the Dutch Copyright Act, indicated by the "Taverne" license above, 


\title{
Microporous calcium phosphate ceramics driving osteogenesis through surface architecture
}

\author{
Jingwei Zhang, ${ }^{1,2 *}$ Davide Barbieri, ${ }^{3 *}$ Hetty ten Hoopen, ${ }^{4}$ Joost D. de Bruijn, ${ }^{3,5,6}$ \\ Clemens A. van Blitterswijk, ${ }^{1}$ Huipin Yuan ${ }^{1,3,7}$ \\ ${ }^{1}$ Department of Tissue Regeneration, MIRA Institute for Biomedical Technology and Technical Medicine, \\ University of Twente, P.O. Box 217, 7500AE Enschede, The Netherlands \\ ${ }^{2}$ Key Laboratory of Advanced Technologies of Materials, Ministry of Education, School of Materials Science and Engineering, \\ Southwest Jiaotong University, Chengdu, People's Republic of China \\ ${ }^{3}$ Xpand Biotechnology BV, Bilthoven, The Netherlands \\ ${ }^{4}$ Biomedical Chemistry, MIRA Institute for Biomedical Technology and Technical Medicine, University of Twente, \\ P.O. Box 217, 7500AE Enschede, The Netherlands \\ ${ }^{5}$ Department of Biomaterials Science and Technology, MIRA Institute for Biomedical Technology and Technical Medicine, \\ University of Twente, P.O. Box 217, 7500AE Enschede, The Netherlands \\ ${ }^{6}$ School of Engineering ans Materials Science (SEMS), Queen Mary University of London, E1 4NS London, United Kingdom \\ ${ }^{7}$ Institute of Physics and Technology, Sichuan University, Chengdu, China
}

Received 28 February 2014; revised 6 June 2014; accepted 10 June 2014

Published online 18 July 2014 in Wiley Online Library (wileyonlinelibrary.com). DOI: 10.1002/jbm.a.35272

Abstract: The presence of micropores in calcium phosphate (CaP) ceramics has shown its important role in initiating inductive bone formation in ectopic sites. To investigate how microporous $\mathrm{CaP}$ ceramics trigger osteoinduction, we optimized two biphasic CaP ceramics (i.e., BCP-R and BCP-S) to have the same chemical composition, equivalent surface area per volume, comparable protein adsorption, similar ion (i.e., calcium and phosphate) exchange and the same surface mineralization potential, but different surface architecture. In particular, BCP-R had a surface roughness $(\mathrm{Ra})$ of $325.4 \pm 58.9$ $\mathrm{nm}$ while for BCP-S it was $231.6 \pm 35.7 \mathrm{~nm}$. Ceramic blocks with crossing or noncrossing channels of $250,500,1000$, and $2000 \mu \mathrm{m}$ were implanted in paraspinal muscle of dogs for 12 weeks. The percentage of bone volume in the channels was not affected by the type of pores (i.e., crossing vs. closed) or their size, but it was greatly influenced by the ceramic type (i.e., BCP-R vs. BCP-S). Significantly, more bone was formed in the channels of BCP-R than in those of BCP-S. Since the two $\mathrm{CaP}$ ceramics differed only in their surface architecture, the results hereby demonstrate that microporous $\mathrm{CaP}$ ceramics may induce ectopic osteogenesis through surface architecture. @ 2014 Wiley Periodicals, Inc. J Biomed Mater Res Part A: 103A: 1188-1199, 2015.

Key Words: bone grafting, calcium phosphate ceramics, microstructure, surface architecture, osteogenesis

How to cite this article: Zhang J, Barbieri D, ten Hoopen H, de Bruijn JD, van Blitterswijk CA, Yuan H. 2015. Microporous calcium phosphate ceramics driving osteogenesis through surface architecture. J Biomed Mater Res Part A 2015:103A:1188-1199.

\section{INTRODUCTION}

Searching for alternatives to autologs bone graft, which is the current gold standard grafting material to heal bone defects, has become a goal of biomedical engineering. ${ }^{1-3}$ Calcium phosphate (CaP) ceramics are applied for bone grafting because their chemical composition resembles the bone mineral phase. ${ }^{4-6}$ Traditionally, CaP ceramics were used as osteoconductive or osteoinductive bone graft substitutes in combination with cells and/or growth factors. For instance, $\mathrm{CaP}$ ceramics delivering mesenchymal stromal cells (MSCs) to the bone defect site could induce bone formation. $^{7}$ Alternatively, a subclass of CaP ceramics with specific physicochemical properties can induce ectopic bone forma- tion without the addition of cells or growth factors through a process defined as "osteoinduction." Such phenomena has been reported in several animal models, where hydroxyapatite (HA) ceramic induced heterotopic bone formation in dogs, ${ }^{8,9}$ baboons, ${ }^{4,10-12}$ rabbits, ${ }^{13}$ mouse, ${ }^{13}$ sheep, ${ }^{14}$ and goats. ${ }^{15,16}$ Similarly, it was shown occurring also in tricalcium phosphate (TCP) ceramics in dogs, ${ }^{4,9,17-20}$ sheep, $^{21}$ and in biphasic calcium phosphate (BCP) ceramics implanted in dogs, ${ }^{5,17,18,22}$ pigs, ${ }^{5}$ sheep, ${ }^{14,23}$ goat, ${ }^{16,24-27}$ rabbits, ${ }^{13,28}$ and baboons. ${ }^{11}$ Previous studies have shown the possible clinical importance of such CaP ceramics by comparing them in both nonosseous and osseous sites. ${ }^{22,29}$ Moreover, a resorbable osteoinductive TCP ceramic has

*These authors contributed equally to this work. 
shown equivalent bone forming ability to autologs bone graft and recombinant human bone morphogenetic protein2 (rhBMP-2) in critical-sized bone defects. ${ }^{21}$ This finding strongly reveals the potential of such specific ceramics to be alternatives to autologs bone grafts.

The available data may have shown the relevance of material properties to its functionality in bone regeneration. Physicochemical modification of $\mathrm{CaP}$ ceramics may represent an approach for bone defect repair. It is well known that the chemistry of CaP ceramics influences on their degradation behavior, which in turn affects osteogenesis. For instance, in a previous study of ours, HA and BCP ceramics were implanted intramuscularly in goats: higher bone incidence and amount were found in the BCP ceramic-which contains the more soluble TCP-as compared to HA ceramic. ${ }^{15}$ The geometry and macrostructural properties of ceramic scaffolds have been shown to play critical roles in bone formation as well. Ripamonti et al showed that bone formation always started from the concave side of the macropores and never from the convex spaces of HA rods and discs. ${ }^{30}$

It is generally accepted that the presence of micropores in $\mathrm{CaP}$ ceramics plays an important role in inducing heterotopic bone formation. For instance, microporous HA ceramics could induce bone formation after subcutaneous ${ }^{8}$ and intramuscular ${ }^{6}$ implantations in dogs, while no bone formed in those HA ceramics lacking of micropores. The microstructure may improve osteoinduction by enlarging the surface area, thus affecting protein adsorption, ion release and mineral deposition. Protein adsorption, that is the adsorption of growth factors including bone morphogenetic proteins (BMPs), ${ }^{31,32}$ is believed to play a crucial role in bone induction. It has therefore been suggested that micropores in CaP ceramics may concentrate higher amounts of growth factors thanks to their enlarged surface area. $^{15,21}$ It was also proposed that the microporous CaP ceramics can enhance the ion exchange processes because of their enlarged surface area, later affecting osteogenic differentiation of MSCs. ${ }^{33}$ The ions (e.g., $\mathrm{Ca}^{2+}$ and $\mathrm{PO}_{4}^{3-}$ ) in the surroundings might trigger the bioactivity of $\mathrm{CaP}$ ceramics, which may later allow bone formation. ${ }^{34}$ In addition, the $\mathrm{Ca}^{2+}$ and $\mathrm{PO}_{4}^{3-}$ in the body fluids could also form a biological apatite layer on the surface of the CaP ceramics. ${ }^{16,35}$ The possible role of the formation of an apatite layer in osteoinduction is supported by the fact that bioactive metals could induce ectopic bone formation. For example, bioactive titanium implants that could get surface mineralization induced bone formation after ectopic implantation, while titanium implants not able to get such mineralization then could not induce any bone formation. ${ }^{35}$

In addition to the improved protein adsorption and ion exchange, micropores in CaP ceramics can generate different surface architectures, which have shown to influence the osteogenic differentiation of MSCs through various physical properties such as surface roughness, ${ }^{36-40}$ the size of surface pattern, ${ }^{41,42}$ and surface morphology. ${ }^{43-45}$ For instance, Fu et al. showed that micropost rigidity can affect cell morphology, focal adhesions, cytoskeletal contractility, and differentiation of stem cells. ${ }^{46}$ In addition, Oh et al. showed the critical role of the nanotube dimensions on osteogenic differentiation of hMSCs in absence of osteogenic inducing media. ${ }^{42}$ Finally, Dalby et al. demonstrated that nanoscale disorder could stimulate osteogenic differentiation of hMSCs in vitro without osteogenic supplements. ${ }^{45}$ Therefore the role of surface architecture of CaP ceramics in ectopic osteogenesis cannot be excluded. The surface arthitecture could be varied by controlling the sintering temperature of $\mathrm{CaP}$ ceramics: a decrease in grain size and increase in microporosity have shown to positively affect on osteoinductive potential of CaP ceramics. ${ }^{16,21}$ Considering the surface properties, it is known that the presence of a high number of small features on the surface indicates high roughness values.

Therefore, from previous results suggesting that CaP ceramics with small grains trigger heterotopic bone formation, here we expect that CaP ceramics with high roughness will lead to ectopic bone formation. To explore whether the surface architecture affects osteogenesis by microstructured CaP ceramics, we optimized two types of BCP ceramics (i.e., BCP-R and BCP-S) to have the same chemical composition, equivalent surface area per volume, comparable protein adsorption, similar ions (e.g., $\mathrm{Ca}^{2+}$ and $\mathrm{PO}_{4}^{3-}$ ) exchange and same surface mineralization potential, but different surface architecture. We then compared their capacity to induce osteogenesis in a canine osteoinduction model.

\section{MATERIALS AND METHODS}

\section{Preparation and optimization of BCP ceramics}

Two types of BCP, namely BCP-R and BCP-S, were prepared from the same $\mathrm{CaP}$ apatite powder with a $\mathrm{Ca} / \mathrm{P}$ ratio of 1.64. BCP-R was obtained by mixing $\mathrm{CaP}$ apatite powder with $0.1 \% \mathrm{H}_{2} \mathrm{O}_{2}$ solution to get slurry, which was subsequently dried at room temperature and sintered at $1150^{\circ} \mathrm{C}$ for $8 \mathrm{~h}$. BCP-S was prepared by isostatically pressing the starting apatite powder in a steel cylinder, with inner diameter of $1.25 \mathrm{inch}$, at a certain pressure for $5 \mathrm{~min}$ at room temperature and thereafter sintering it at $1150^{\circ} \mathrm{C}$ for $8 \mathrm{~h}$. Importantly, the pressure was optimized to get BCP-S having the same protein adsorption as BCP-R (see section "Protein adsorption"): at last the chosen BCP-S was prepared using a pressure of $50 \mathrm{MPa}$. The ceramic samples were then made into three forms. Discs $(\varnothing 10 \times 1 \mathrm{~mm})$ were fabricated using a lathe (Esmeijer, Netherland) and a histological diamond saw (SP-1600, Leica, Germany), while blocks $(7 \times 9 \times 12$ $\mathrm{mm}$ ) were made using a diamond saw (Heathway, England). Afterwards, two types of channels (i.e., crossing and noncrossing) with different diameters of 250,500, 1000, and $2000 \mu \mathrm{m}$ were made along the shortest side of the BCP blocks using drills with the required diameter. BCP-R ceramic implants had both crossing and noncrossing channels, while BCP-S ceramic implants only had noncrossing channels. Because of technical challenges, it was not possible to obtain crossing channels with a diameter of $250 \mu \mathrm{m}$ in BCP-R. Granules (size 1-2 mm) were obtained by crushing and sieving the ceramics. The crossing channels were made to study the possible role of pore interconnectivity in bone induction. All the samples were ultrasonically cleaned 
with acetone, $70 \%$ ethanol and demineralized water, then dried at $80^{\circ} \mathrm{C}$ and sterilized with gamma irradiation (Isotron, Netherland BV, Ede, The Netherlands) before further use.

\section{Physicochemical characterization of the ceramics}

The chemical composition of the samples was determined with X-ray diffraction (XRD; Rigaku, Japan). The HA/ $\beta$-TCP weight ratios in the $\mathrm{BCP}$ ceramics were determined with a calibration line obtained from internal standard powders with known HA/ $\beta$-TCP weight ratios. The surface microstructure of the BCP ceramics was studied with scanning electron microscope (SEM; XL30, ESEM-FEG, Philips, Eindhoven, The Netherlands) in the secondary electron mode. The micro-porosity, micro-pore size distribution, and specific surface area of the ceramic blocks were measured using a mercury intrusion porosimeter (MP; Auto Pore IV 9500, Micromeritics European Analysis Service, Monchengladbach, Germany). The density of the ceramics was measured with the weight/volume method using the ceramic discs. To better evaluate the surface properties, we calculated the surface area per volume as the product between the specific surface area measured with mercury intrusion and the measured density of the ceramic. The surface roughness of the ceramic discs was analyzed with atomic force microscopy (AFM; Bioscope Catalyst AFM, Bruker AXS, Wormer, the Netherlands) using dual scans in tapping mode, at a scan frequency of $1 \mathrm{~Hz}$, on areas of $10 \times 10 \mu \mathrm{m}$ with a MikroMarsch NCS36 cantilever (total tip height 20$25 \mu \mathrm{m}$, tip radius $10 \mathrm{~nm}$ and full type cone radius of $40^{\circ}$, spring constant $1.75 \mathrm{~N} / \mathrm{m}$ ). Obtained images were filtered from signal noise and then analyzed with SPIP software (v5.1.11, Image Metrology A/S, Hørsholm, Denmark). The surface roughness was estimated in terms of roughness average (Sa) and root mean square (Sq). Further, measurements on the profile height changes as compared to the zero-plan were also taken and plotted as distribution.

\section{Protein adsorption}

Fetal bovine serum (FBS, Lonza, Germany) and bovine serum albumin (BSA, Sigma) were diluted in 25 ppm aqueous $\mathrm{NaN}_{3}$ solution and sterilized with $0.22 \mu \mathrm{m}$ filter to get the solutions of FBS $(0.25 \%)$ and BSA $(100 \mu \mathrm{g} / \mathrm{mL})$. After immersing the discs in the solutions ( $3 \mathrm{~mL}$ per disc, $n=5$ per material) at $37^{\circ} \mathrm{C}$ for $24 \mathrm{~h}$, the remaining proteins in the solutions were measured with the QuantiPro ${ }^{\mathrm{TM}}$ BCA assay kit (Pierce, The Netherlands) following the manufacturer's guidelines and absorbance was measured with a spectrophotometer (AnthosZenyth 3100, AnthosLabtec Instruments GmbH, Salzburg, Austria) at $595 \mathrm{~nm}$. The amount of proteins adsorbed from FBS solution onto the discs (microgram of protein per disc) was estimated through a calibration serum protein curve using FBS after determining the total proteins content in pure FBS (i.e., $33.78 \pm 0.64 \mathrm{mg} / \mathrm{mL}$ ). In the meantime, a calibration line for BSA was built with a series of concentrated BSA solutions. All measured values were expressed as mean \pm standard deviation.

\section{rhBMP-2 adsorption}

A solution of rhBMP2 (500 ng/mL) was prepared by diluting rhBMP-2 (Reborne, Shanghai) in the basic medium (BM) containing Dulbecco's modified Eagle's medium (DMEM; Gibco, Invitrogen, UK), 10\% FBS and 1\% penicillin/streptomycin (100 U/mL penicillin, $100 \mathrm{mg} / \mathrm{mL}$ streptomycin; Gibco, Invitrogen, UK). The ceramic discs were then soaked in the medium ( $3 \mathrm{~mL}$ per disc, $n=5$ per material) at $37^{\circ} \mathrm{C}$ in humid atmosphere with $5 \% \mathrm{CO}_{2}$ for $24 \mathrm{~h}$. The discs were stored at $-80^{\circ} \mathrm{C}$ for at least $12 \mathrm{~h}$ after being washed with PBS three times. Thereafter $0.5 \mathrm{~mL}$ of $1 \%$ triton was add to each sample and kept at $4{ }^{\circ} \mathrm{C}$ for at least $12 \mathrm{~h}$ and followed by ultrasonically shaking for $5 \mathrm{~min}$. Finally, rhBMP-2 content in the supernatant was measured with BMP-2 Elisa kit (R\&D, UK) following the manufacturer's instructions and absorbance was measured with a spectrophotometer at 450 nm. The rhBMP-2 adsorption was estimated through a standard calibration rhBMP-2 curve and expressed as mean \pm standard deviation.

\section{Ion exchange}

Ceramic discs were soaked in BM ( $3 \mathrm{~mL}$ per disc, $n=5$ per material) at $37^{\circ} \mathrm{C}$ in humid atmosphere with $5 \% \mathrm{CO}_{2}$ for 24 h. Calcium and phosphate contents in the solutions were measured and compared to the control (i.e., solution with no sample). Calcium and phosphate ion concentration were measured with QuantiChrom ${ }^{\mathrm{TM}}$ Calcium assay kit (BioAssay, USA) and phosphoWork ${ }^{\mathrm{TM}}$ Colorimetric Phosphate Assay Kit (AATBioquest, USA), respectively following the manufacturer's guidelines. Thereafter, absorbance was measured with spectrophotometer at $620 \mathrm{~nm}$. Both calcium and phosphate contents were expressed as mean \pm standard deviation.

\section{Surface mineralization}

Simulated body fluid (SBF) was prepared according to Ref. [47 by dissolving reagent grade chemicals in distilled water strictly in the following order: $\mathrm{NaCl}, \mathrm{NaHCO}_{3}, \mathrm{KCl}$, $\mathrm{K}_{2} \mathrm{HPO}_{4} \cdot 3 \mathrm{H}_{2} \mathrm{O}, \mathrm{MgCl}_{2} \cdot 6 \mathrm{H}_{2} \mathrm{O}, \mathrm{CaCl}_{2}$ (Ca ion standard solution, $0.1 M$, Metrohm) and $\mathrm{Na}_{2} \mathrm{SO}_{4}$. The solution was then buffered to pH 7.4 at $36.5^{\circ} \mathrm{C}$ using Tris $\left(\left(\mathrm{CH}_{2} \mathrm{OH}\right)_{3} \mathrm{CNH}_{3}\right)$ and $1 M \mathrm{HCl}$. The final solution had an ion concentration $(\mathrm{mM})$ as follows: $\mathrm{Na}^{+}, 142 ; \mathrm{K}^{+}, 5 ; \mathrm{Mg}^{2+}, 1.5 ; \mathrm{Ca}^{2+}, 2.5 ; \mathrm{Cl}^{-}$, 147.8; $\left(\mathrm{HCO}_{3}\right)^{-}, 4.2 ;\left(\mathrm{HPO}_{4}\right)^{2-}, 1 ;\left(\mathrm{SO}_{4}\right)^{2-}, 0.5$. Fifty granules $(1-2 \mathrm{~mm})$ of each material were soaked in $200 \mathrm{~mL}$ of $\mathrm{SBF}$ at $37 \pm 1^{\circ} \mathrm{C}$ for up to 1 week. A minimum of 10 granules were taken out at each time point of $1,2,4$, and 7 days. They were rinsed five times with distilled water and dried at room temperature. The mineralization of the BCP ceramics was observed with SEM. Four spots were randomly selected from each granule. The mineralization level of the materials was ranked as follows: (a) no mineralization: all the spots were completely bare; (b) few mineralization: one (or more) of the spots had thin and not uniform mineralized layers; and (c) full mineralization: all the spots were covered by thick and uniform mineralized layers. For each classification group, the number of granules was 
counted and plotted on a histogram as percentage on the total granules considered.

\section{Evaluation of osteoinduction}

Animal experiments. Following the permission of the local animal care committee (Animal Center, Sichuan University, Chengdu, China), ceramic blocks ( $n=8$ per ceramic) were implanted in the para-spinal muscles of 8 adult male dogs (mongrel, 10-15 kg) for 12 weeks. The surgical operation was performed under general anesthesia by abdominal injection of sodium pentobarbital $(30 \mathrm{mg} / \mathrm{kg}$ body weight) and sterile conditions. Following the surgeries, buprenorphine $(0.1 \mathrm{mg} / \mathrm{animal})$ was intramuscular injected to the dogs for 2 days to relieve pain, while penicillin $(40 \mathrm{mg} / \mathrm{kg})$ was intramuscular injected for three consecutive days to prevent infection. After operation, the animals were allowed for full weight bearing and received normal diet.

Histological processing. After 12 weeks the animals were sacrificed with a celiac injection of excessive amount of pentobarbital sodium. Implants were then harvested with the surrounding tissues and fixed in $4 \%$ buffered formaldehyde solution $(\mathrm{pH}=7.4)$ at $4{ }^{\circ} \mathrm{C}$ for one week, and embedded in methyl methacrylate (MMA, K-plast, LTI Netherland, Bilthoven, the Netherlands) after dehydration in a series of gradient ethanol solutions. Serial nondecalcified sections with an average thickness of $15 \mu \mathrm{m}$ were obtained without interruption using a microtome (SP-1600, Leica, Germany) equipped with diamond saw blade having an approximate thickness of $280 \mu \mathrm{m}$ and a knurled screw to control the thickness of the sections. Being the sectioning done serially, the distance between consecutive sections is $\sim 280 \mu \mathrm{m}$ due to loss of material by the blade. Each slide was stained with $1 \%$ methylene blue (Aldrich) and $0.3 \%$ basic function (Aldrich). Sections were also prepared from MMA-embedded ceramic blocks (not implanted) to be used as controls.

Histological and histomorphometric analysis. The histological sections were observed with light microscopy (Nikon Eclipse E200, Tokyo, Japan) with respect to tissue formation in the channels. The sections were then scanned using a slide scanner (Dimage Scan Elite 5400II, Konica Minolta Photo Imaging Inc, Tokyo, Japan) to obtain overview images for histomorphometrical analysis, which was performed using Adobe Photoshop Elements 4.0 software. The channel area was selected as a region of interest and the corresponding number of pixels was read as ROI. Then the bone tissue area was pseudo-colored and its respective pixels were counted as $\mathrm{B}$. The percentage of bone area in the channel (B\%) was determined as B\% = B*100/ROI and the results were presented as mean and standard deviation of all the sections taken at the same depth from all the samples. As shown in the aforementioned equation, we normalized the bone area to the ROI of the corresponding channel to make the comparison of bone formation among the channels with different dimension possible. The ROI of the channels in the control ceramic blocks was measured as well, and the resorption rate (R\%) of the ceramics after explant was determined as $\mathrm{R} \%=$
(ROI of the control-ROI of the explants)*100/(ROI of the control). The measurements were taken both at the openings and in the central region of the channels.

\section{Statistical analysis}

Statistical analysis was performed using a one-way ANOVA followed by a Tukey's multiple comparison test or paired $t$ test. A value of $p<0.05$ was considered as significant difference.

\section{RESULTS}

\section{Material characteristics}

The XRD patterns of the ceramics are given in Figure 1(a), which shows the two BCP ceramics had similar chemistry consisting of $80 \pm 3$ wt $\%$ HA and $20 \pm 3$ wt $\% \beta$-TCP. The SEM observation demonstrated a rougher surface of BCP-R [Fig. 1(d)] than that of BCP-S [Fig. 1(c)]. This observation was further confirmed by AFM images [Fig. 1(e,f)]. Smaller pores could also be observed on BCP-S than BCP-R as confirmed also by mercury intrusion test [Fig. 1(b)]. The average roughness (Sa) and the root mean square $(\mathrm{Sq})$ resulted significantly higher in BCP-R than BCP-S ( $p=0.0014$ and $p$ $=0.0019$, respectively) indicating that the former material presents a topography having larger and deeper variability in its peaks and hollows heights over the area [Fig. 1(h)]. These results are corroborated by the distribution of surface heights [Fig. 1(g)], which is larger for BCP-R. Interestingly, the distribution of surface heights on BCP-R presents a lager tail on the right as compared to BCP-S, which might be correlated with the preparation method of BCP-S involving a step of isostatic pressure that could have flattened the surface. In addition, the mercury intrusion results showed the two BCP ceramics had different porosity and distribution of micropore size. A micropore range of 0.3 and $1.3 \mu \mathrm{m}$ with a peak at $0.9 \mu \mathrm{m}$ for BCP-R, whereas BCP-S had micropore range from 0.3 to $0.7 \mu \mathrm{m}$ with a peak at $0.6 \mu \mathrm{m}$ [Fig. 1(b)]. The total microporosity was higher for BCP-R (43\%) than for BCP-S (28\%). Mercury intrusion data revealed also that the surface area per volume of BCP-R and BCP-S were the same (Table I).

\section{Protein adsorption assay}

The amount of protein absorbed by the two ceramics is shown in Figures 2(c, d, e), where no significant differences between BCP-R and BCP-S with respect to adsorption of BSA $(p=0.702)$, of proteins in FBS $(p=0.387)$, and of rhBMP-2 ( $p=0.632$ ) were observed. These results might be explained by the fact that the two ceramics have the same surface area.

\section{Calcium and phosphate ions assay}

Changes in calcium and phosphate ion concentrations in BM were evaluated [Fig. 2(a,b)]: instead of releasing calcium and phosphate ions into the medium, both ceramics adsorbed ions from the medium within $24 \mathrm{~h}$. However, BCP$\mathrm{R}$ and BCP-S adsorbed similar amounts of calcium and phosphate ions and no significant differences were observed (calcium: $p=0.153$, phosphate: $p=0.088$ ). 

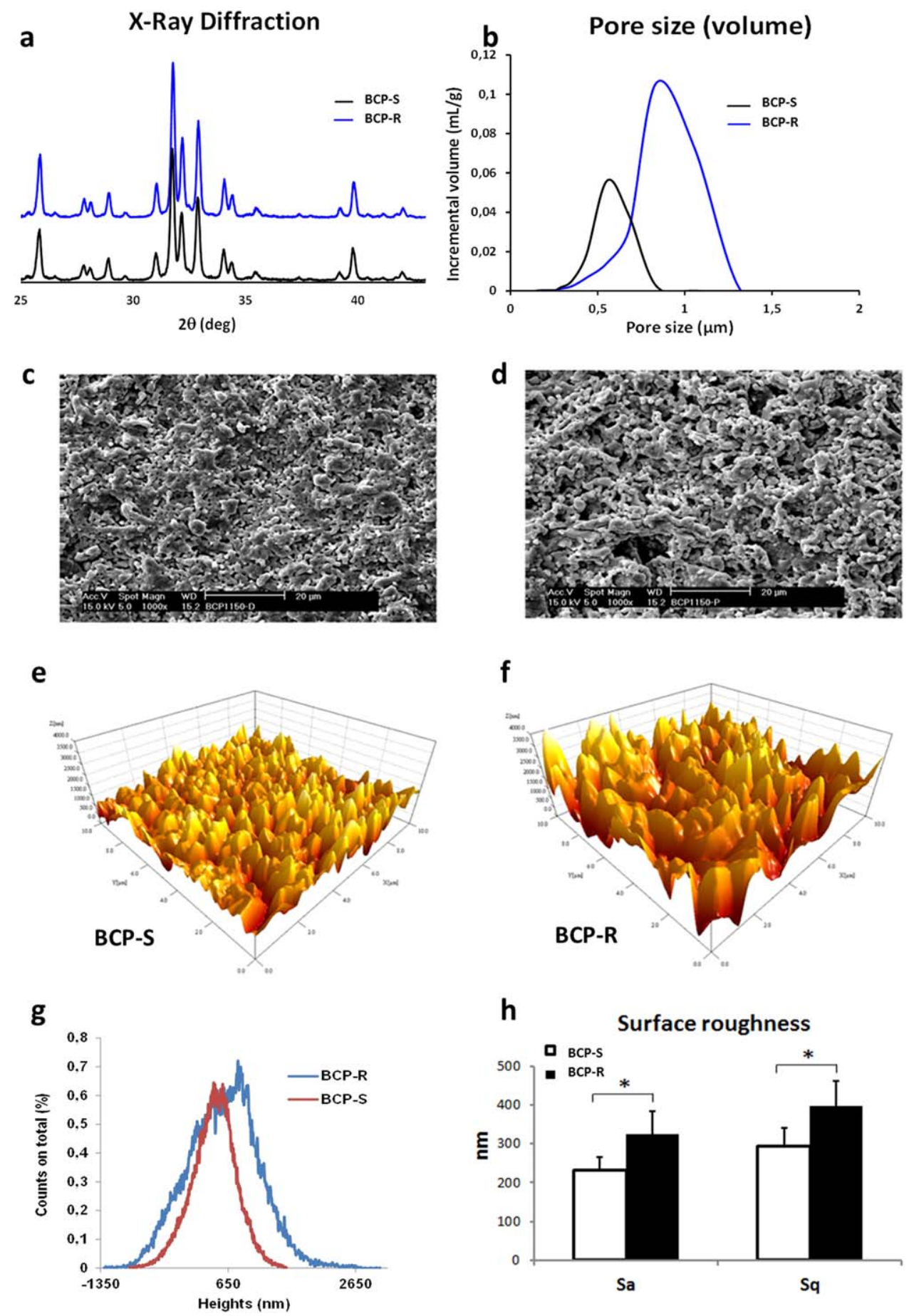

FIGURE 1. (a) XRD pattern of the two ceramics, showing that BCP-S and BCP-R have the same chemistry. (b) Micropore distribution of BCP-S and BCP-R as obtained from mercury intrusion measurements. It can be seen that BCP-S has smaller micropore size than BCP-R. The surface microstructure of (c) BCP-S and (d) BCP-R was observed with SEM. AFM allows evaluating the surface roughness of (e) BCP-S and (f) BCP-R. The height distributions of the microstructured surface of the two ceramics is shown in (g). Histograms in (h) allow the comparison of the measured surface roughness average (Sa) and root mean square $(\mathrm{Sq})$ between the two ceramics. Statistically significant differences are marked by * for $p<0.05$. [Color figure can be viewed in the online issue, which is available at wileyonlinelibrary.com.]

\section{Surface mineralization}

Mineralization on the BCP ceramics was observed as early as after soaking in SBF for one day [Fig. 3(a,b)], and the amount of mineralization increased during time finally leading to thick layers of apatite that uniformly covered the surface of all the samples after seven days [Fig. $3(\mathrm{c}, \mathrm{d})]$. The trend of surface mineralization over time is illustrated in Figure 3(e), where no significant differences between the two BCP ceramics were observed after seven days. 
TABLE I. Density, Specific Surface Area and Surface Area per Volume of the Two BCP Ceramics: The Density and the Specific Surface Area Data Were Experimentally Measured and Used to Calculate the Surface Area per Volume that Resulted to be the Same for the Two Ceramics

\begin{tabular}{cccc}
\hline & $\begin{array}{c}\text { Density } \\
(\mathrm{g} / \mathrm{mL})\end{array}$ & $\begin{array}{c}\text { Specific Surface } \\
\text { Area }\left(\mathrm{m}^{2} / \mathrm{g}\right)\end{array}$ & $\begin{array}{c}\text { Surface Aarea } \\
\text { per Volume }\left(\mathrm{m}^{2} / \mathrm{mL}\right)\end{array}$ \\
\hline BCP-R & $1.758 \pm 0.026$ & 1.057 & 1.859 \\
BCP-S & $2.242 \pm 0.026$ & 0.825 & 1.854 \\
\hline
\end{tabular}

\section{Ectopic bone formation}

A total of eight samples per ceramic were intramuscularly implanted in eight dogs for 12 weeks, and all were retrieved. Histological observations demonstrated that bone formed in most channels of BCP-R [Fig. 4(b,d)], while in
BCP-S little bone amounts were found in few channels and fibrous tissue was dominant [Fig. 4(a,c)]. Bone grew tight to the wall of the channels [Fig. 4(d)]. The distribution of the newly formed bone along the crossing channels with different diameters (i.e., $500 \mu \mathrm{m}, 1000 \mu \mathrm{m}$, and $2000 \mu \mathrm{m}$ ) of BCP-R is shown in Figure 4(e). It could be seen that similar trends in the distribution of new bone exist among the different channels: no bone formation at the openings (i.e., at 0 and $7000 \mu \mathrm{m}$ on the $x$-axis); bone formation always started at about $500 \mu \mathrm{m}$ far from both openings (i.e., at 500 and $6500 \mu \mathrm{m}$ on the $x$-axis); high amount of bone formation was observed in the central part of the channels (i.e., between 750 and $6000 \mu \mathrm{m}$ on the $x$-axis). Furthermore, it appeared that higher amount of bone formed in the channels with $1 \mathrm{~mm}$ diameter rather than in the others, but no significant differences in the bone amount were seen since
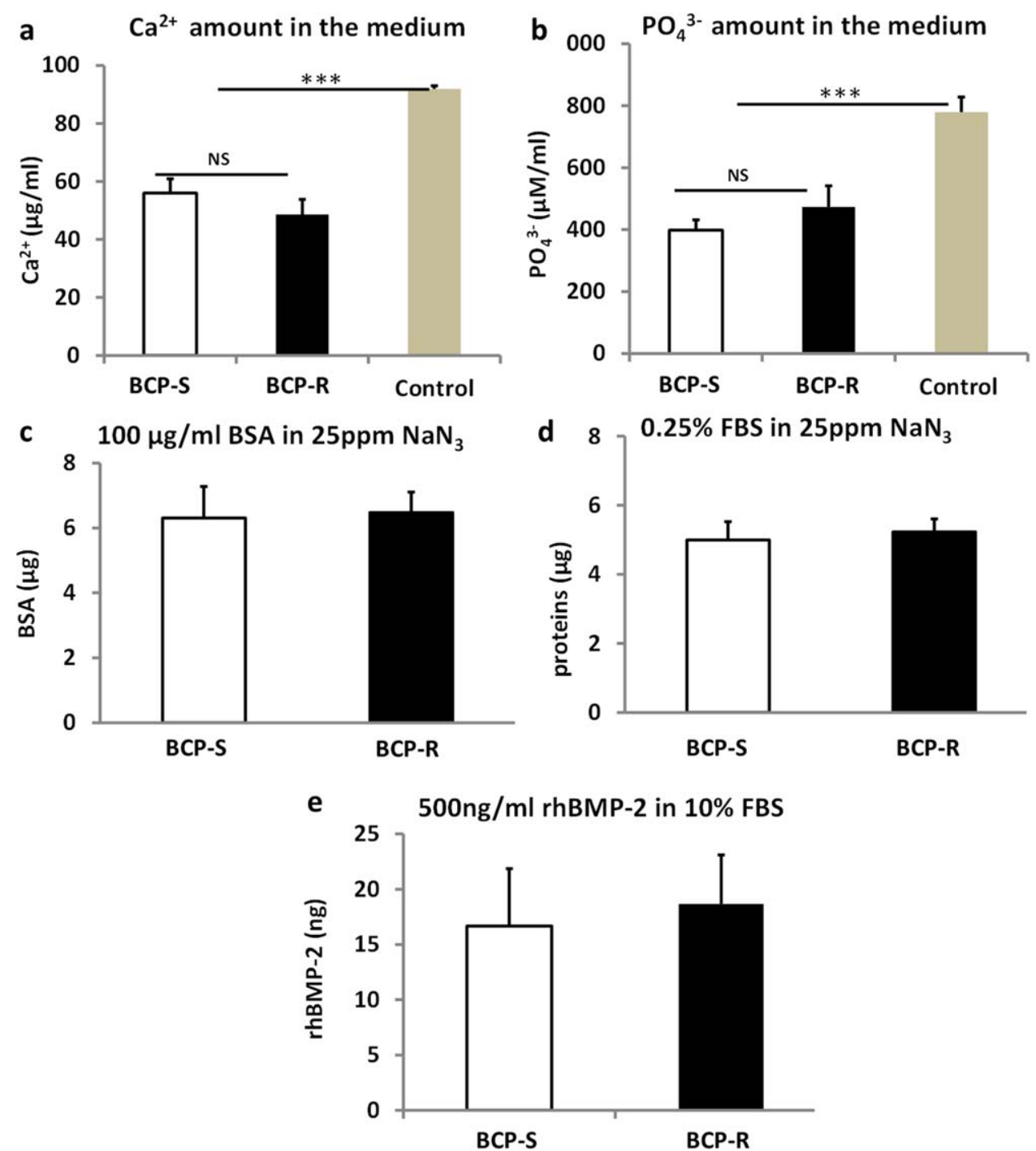

FIGURE 2. (a) $\mathrm{Ca}^{2+}$ and (b) $\mathrm{PO}_{4}^{3-}$ concentrations in culture medium after soaking the two ceramics' discs for 24 h: they were significantly lower than the control medium in both cases, but differences in $\mathrm{Ca}^{2+}$ and $\mathrm{PO}_{4}^{3-}$ amounts in the medium with $\mathrm{BCP}-\mathrm{S}$ and $\mathrm{BCP}-\mathrm{R}$ were not significant. Protein adsorption of the ceramic discs after soaking in (c) BSA, (d) FBS, and (e) rhBMP-2 solutions, indicating that BCP-S and BCP-R have similar protein adsorption potential. Any statistically significant difference is marked with *** for $p<0.001$. [Color figure can be viewed in the online issue, which is available at wileyonlinelibrary.com.] 
a

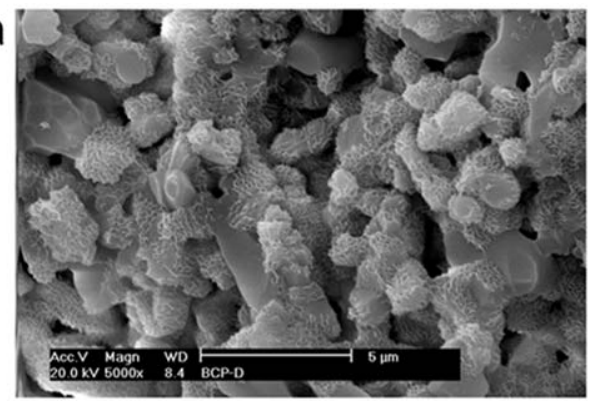

C

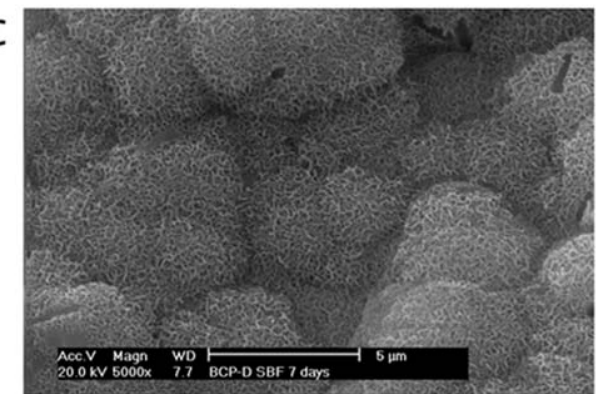

e

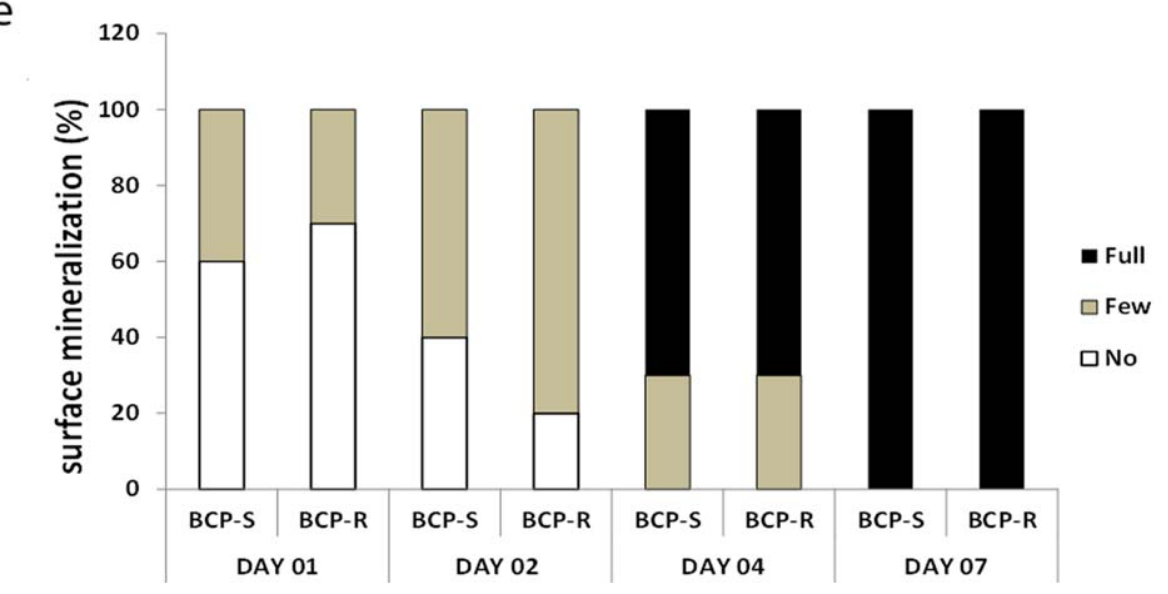

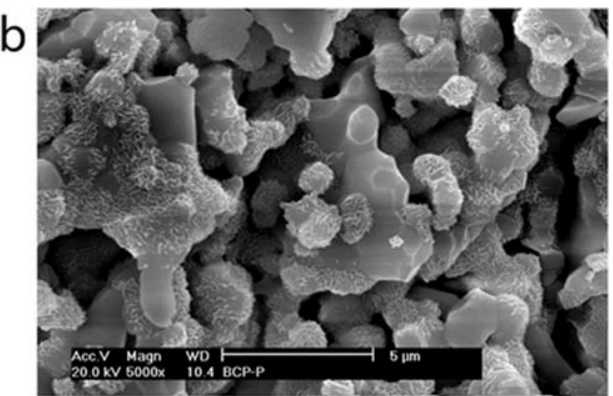

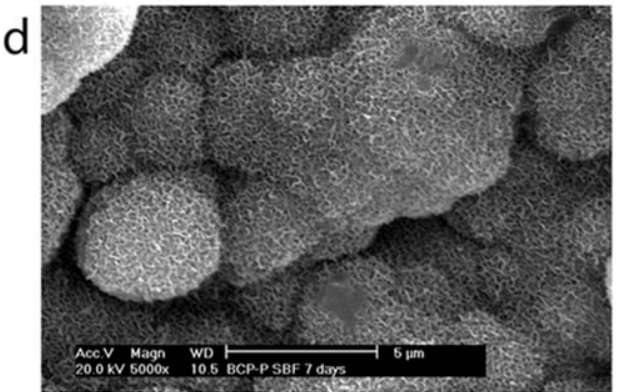

Full

FIGURE 3. Surface mineralization of BCPs after soaking in SBF solution. SEM images of surface mineralization on BCP-S with (a) few and (c) full surface mineralization and BCP-R with (b) few and (d) full surface mineralization. (e) Percentage of BCPs ceramics with no, few and full surface mineralization at days $1,2,4$, and 7 . [Color figure can be viewed in the online issue, which is available at wileyonlinelibrary.com.]

the standard deviation was high $(p>0.05)$. Table II shows the amount of bone formation in each channel of the BCP ceramics. In BCP-R ceramics: with the same diameter, the type of channel (i.e., crossing and noncrossing) does not affect the amount of bone formation $(p>0.05)$; within the same type of channel, the diameter of the channel does not affect the amount of bone formation either $(p>0.05)$. However, the amount of bone formation was significantly affected by the ceramic type (i.e., BCP-R vs. BCP-S), where significantly higher amounts of bone formed in the channels of BCP-R $(p<0.01$ or $p<0.001)$. The histological overviews [Fig. $4(a, b)]$ show that the channels of both BCP ceramics retained their shape after a 12-week implantation indicating no obvious resorption of both ceramics in vivo. The quantitative data confirmed this observation (Table III) where no significant resorption was seen in both ceramics. In particular, the measurements showed no effect of the diameter or region (i.e., at the openings and in the central sector) of the channel on the ceramics resorption.

\section{DISCUSSION}

In this study, we used optimized BCP ceramics to investigate whether the surface architecture is playing a role in material-directed osteoinduction. We could minimize the number of possible influencing factors and make sure that the two ceramics differed only in their surface architecture. After a 12-week intramuscular implantation, BCP-R gave rise to abundant bone formation while BCP-S could induce the formation of a little amount of bone. The results presented herein thus indicate an important role of surface architecture in the osteogenesis process by CaP ceramics.

Chemistry, ${ }^{21,22,42}$ macrostructure, ${ }^{11,48}$ and microstructure $^{16,49,50}$ have been suggested to play roles in material dependent osteoinduction. The possible influence of chemistry and macrostructure could be excluded in our study. The 
a

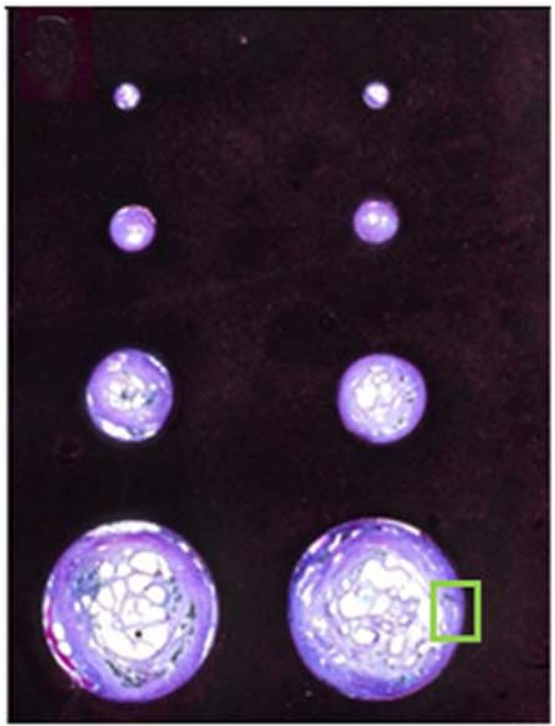

C

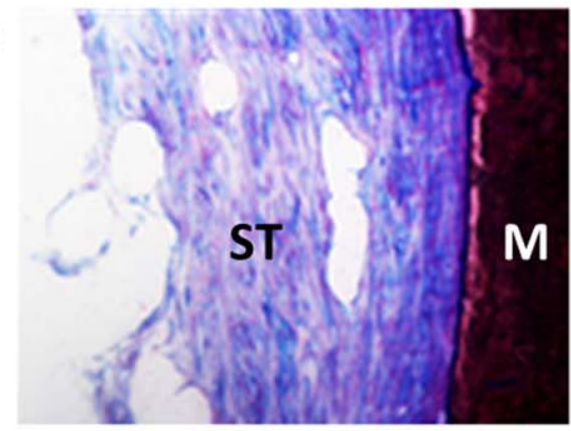

b

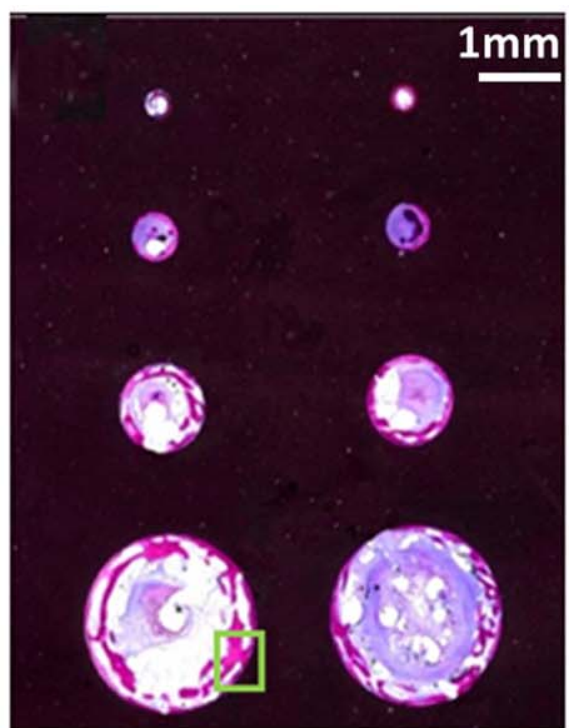

d

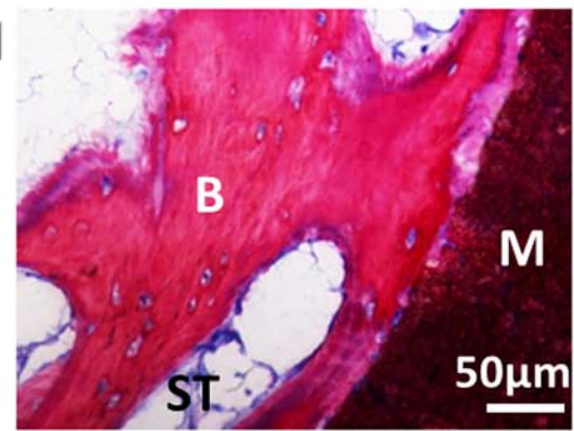

e

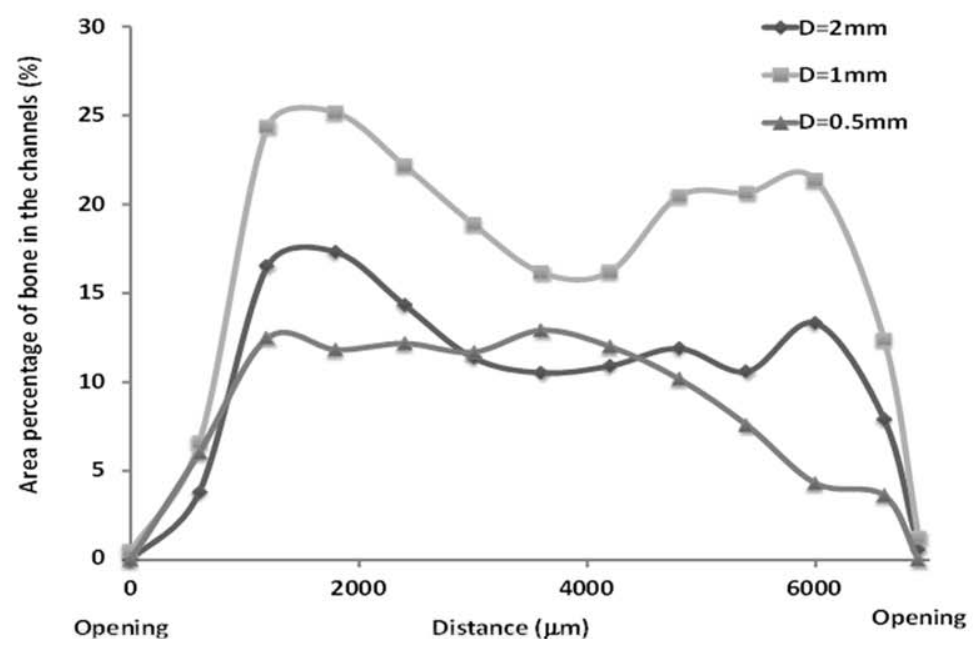

FIGURE 4. Histology of the BCP ceramics ( $a$ and $c: B C P-S ; b$ and d: BCP-R) after 12 weeks in muscle of dogs. The green rectangles in (a) and (b) highlight the areas observed with light microscope in (c) and (d). Figure (e) shows bone formation area along the crossing channels in BCP-R. Legend of symbols: ST stands for soft tissues, M for material, and B for bone. [Color figure can be viewed in the online issue, which is available at wileyonlinelibrary.com.]

two BCP ceramics were made from the same CaP powder and, as shown in the XRD patterns, both BCP ceramics had the same composition with $80 \pm 3 \%$ wt HA and $20 \pm 3 \%$ wt $\beta$-TCP. This indicated that the different manufacture methods did not affect the final chemistry of the BCP ceramics. The macrostructure of the two BCP ceramic implants was kept equal: both BCP ceramics contained noncrossing channels with different diameters (i.e., 250, 500, 1000 , and $2000 \mu \mathrm{m}$ ), and the channels were created in the same positions in all the blocks.

The histological analysis showed that the newly formed bone was not on the surface of the implants, but it always 
TABLE II. A Summary of the Bone Forming Ability In Vivo for the Ceramics Studied

\begin{tabular}{|c|c|c|c|c|}
\hline Samples & & & Bone Incidence (\%) & Bone in Pores (\% wt) \\
\hline \multirow[t]{7}{*}{ BCP-R } & Noncrossing $(\varnothing: \mathrm{mm})$ & 2 & 100 & $11.0 \pm 3.8$ \\
\hline & & 1 & 100 & $17.7 \pm 5.7$ \\
\hline & & 0.5 & 100 & $7.9 \pm 9.4$ \\
\hline & & 0.25 & 75 & $15.5 \pm 19.5$ \\
\hline & Crossing ( $\varnothing: \mathrm{mm})$ & 2 & 100 & $14.3 \pm 5.8$ \\
\hline & & 1 & 100 & $22.3 \pm 9.6$ \\
\hline & & 0.5 & 87.5 & $6.8 \pm 9.4$ \\
\hline \multirow[t]{4}{*}{ BCP-S } & Noncrossing $(\varnothing: \mathrm{mm})$ & 2 & 50 & $0.6 \pm 1.1$ \\
\hline & & 1 & 25 & $0.9 \pm 2.4$ \\
\hline & & 0.5 & 62.5 & $1.8 \pm 2.3$ \\
\hline & & 0.25 & 31.25 & $1.8 \pm 3.7$ \\
\hline
\end{tabular}

It can be observed that the bone incidence as well as the newly formed bone volume were significantly higher in BCP-R than BCP-S when considering the case of closed channels (i.e., with only one opening). The presence of a second opening in the channels (i.e., two sides open case) did not significantly change the in vivo performance of BCP-R.

formed inside the channels suggesting the important role of macrostructure in osteoinduction. This result is consistent with a previous study, ${ }^{19}$ where it was concluded that a concave structure is necessary for osteoinduction in CaP ceramics. To further investigate the effect of macrostructure dimension on bone formation, we fabricated both BCP ceramic implants with different channels' diameters. When analyzing the ceramics, no significant difference was observed in both the bone incidence and the bone amount among the channels having different diameter. It is worthy of notice that this fact was found for both BCP-R and BCP-S, therefore the diameter of the channels did not seem to be essential for bone ingrowth in the tested range. However, the measured percentage of bone in the 12-week samples could not address the dynamic metabolism of the formed bone regarding its growth towards the center of the channels and its remodeling, therefore the possible influence of the channels' diameter on bone metabolism could not be excluded. It may well be that, at other time points such as later than 12 weeks, the smaller channels would have more bone fill than the larger ones as the latter will take longer to be fully colonized by bone tissue. Furthermore, we observed that there was no significant difference between crossing and noncrossing channels in BCP-R, which is in good agreement with a previous study ${ }^{12}$ where it was claimed that interconnected macropores are not necessary for osteoinduction. However, the histological results showed that the incidence and amount of bone induced by BCP-S were lower than BCP-R regardless of the channel diameter (Table II). Therefore, the surface microstructure may have played roles as main determinant of the osteoinductive potential of the BCP ceramics, which was already shown in several studies. ${ }^{16,46,49}$ It is generally suggested that microporous CaP ceramics affects bone formation by virtue of its enlarged surface area since it would result in higher protein adsorption (e.g., BMP-2), higher calcium and phosphate ions release and induced surface mineralization, or their combinations.

Both BCP-R and BCP-S used in this study had the same volume and equal surface area as shown in Table I. Therefore, the surface area was not the main factor influencing the bone forming potential. Meanwhile, the two BCP ceramics adsorbed similar amounts of proteins from BSA and FBS solutions, and they also could uptake rhBMP-2 from cell culture medium (Fig. 4). These results confirm the fact that surface area of $\mathrm{CaP}$ ceramics influences the protein adsorption. Having equal surface area, BCP-R and BCP-S adsorbed equivalent amounts of proteins regardless of the type of protein. The results also show that the protein adsorption could not be appointed as the main determinant for osteoinduction, since bone formation was different between BCP-R and BCP-S which adsorbed the same amount of proteins.

It has been reported that extracellular calcium and phosphate significantly influenced the growth and osteogenic differentiation of $\mathrm{MSCs},{ }^{48}$ meanwhile the calcium and phosphate supplementation promoted bone cell mineralization. ${ }^{16}$ It has been also suggested that have been made the dissolution of calcium and phosphate ions can be improved when biomaterials are precoated with $\mathrm{CaP}$ apatite layers. When titanium alloy was covered by an apatite layer, it could dissolve and release ions that can favor osteogenic

TABLE III. A Summary of Ceramic Resorption In Vivo (as Measured for the Noncrossing Channels in Both Ceramics), Which Did Not Occur Regardless of the Ceramic Type or Channel Diameter

\begin{tabular}{|c|c|c|c|c|c|c|c|c|c|}
\hline & & \multicolumn{4}{|c|}{ Peripheral Region of the Channels ( $:$ : $\mathrm{mm}$ ) } & \multicolumn{4}{|c|}{ Central Region of the Channels ( $\Phi: \mathrm{mm}$ ) } \\
\hline & & 2000 & 1000 & 500 & 250 & 2000 & 1000 & 500 & 250 \\
\hline $\begin{array}{l}\text { Resortpion } \\
\text { rate (\%) }\end{array}$ & $\begin{array}{l}\text { BCP-R } \\
\text { BCP-S }\end{array}$ & $\begin{array}{r}0.28 \pm 1.47 \\
2.6 \pm 2.49\end{array}$ & $\begin{aligned}-1.42 & \pm 2.27 \\
3.49 & \pm 3.5\end{aligned}$ & $\begin{array}{r}-1.21 \pm 5.71 \\
1.71 \pm 3.39\end{array}$ & $\begin{array}{l}-3.24 \pm 4.42 \\
-4.32 \pm 2.13\end{array}$ & $\begin{array}{l}0.23 \pm 2.27 \\
0.09 \pm 1.16\end{array}$ & $\begin{array}{l}-0.26 \pm 3.34 \\
-0.11 \pm 2.75\end{array}$ & $\begin{array}{r}-1.99 \pm 5.10 \\
1.68 \pm 4.65\end{array}$ & $\begin{array}{l}1.28 \pm 2.29 \\
1.34 \pm 1.49\end{array}$ \\
\hline
\end{tabular}


differentiation of progenitor cells ${ }^{51}$ indicating a key role in the CaP dissolution. It is therefore possible that the microporous CaP ceramics used in our study initiated inductive bone formation via ion release during material resorption. However, no obvious resorption of both BCP ceramics was observed in this study. The reason could be that the TCP content in BCP ceramics was too low $(20 \%)$ or the implantation time was too short (12 week) to allow the resorption of the ceramics. Moreover, both BCP-R and BCP-S, instead of releasing, adsorbed similar amount of calcium and phosphate ions from culture medium after $24 \mathrm{~h}$ in vitro. Therefore, the degradation rate of the materials and the $\mathrm{CaP}$ ions release was not the affecting factors in BCP-R ceramicinduced osteogenesis.

The ability to get surface mineralization has also been suggested being important in ectopic osteogenesis because ectopic bone formation was observed quite often in materials that can easily mineralize. Winter and Simpson reported that ectopic bone formation induced by a polymeric material occurred after surface mineralization of the implant. ${ }^{52}$ Fujibayashi et al. studied the in vivo osteoinductivity of titanium implants, which could or not surface mineralize in vitro in SBF. The results demonstrated that those implants that induced an apatite layer formation in vitro had osteoinductive potential in vivo. ${ }^{35}$ Similarly, Barbieri et al. reported the role of surface mineralization in vitro in materialdirected bone induction. They prepared poly (D,L-lactide) and nanosized apatite composites with various apatite contents that were used to test in vivo osteoinduction. The results showed that only composites with at least $40 \% \mathrm{wt}$ apatite content could surface mineralize in vitro and induced bone formation in vivo. ${ }^{53}$ Besides the spontaneous formation of mineralized layers by natural precipitation of ions from biological fluids, precoating biomaterials with $\mathrm{CaP}$ layers has shown to improve their biological activity. For example, polycaprolactone/TCP composites with HA-like coating allowed not only better adhesion and proliferation of porcine BMSCs as compared to noncoated counterparts ${ }^{54}$ but also better osteogenic differentiation as the expression levels of various osteogenic indicators were improved. The authors suggested that such apatite-like coating layers would mimic the bone environment thus direct cells towards bone phenotypes. ${ }^{54}$ When a polymer, i.e., polycaprolactone, was coated with a CaP layer and then cultured with osteoblasts, ${ }^{55}$ it could induce ectopic bone formation subcutaneously. The same study observed significant lower performances of the noncoated polymer indicating a crucial role of apatite-like layers in bone induction. However, our results showed that both BCP-R and BCP-S mineralized in vitro with similar trends, thus the possible influence of surface mineralization on their different osteoinductivity could be excluded.

Taken together, the role of surface architecture (as characterized by surface roughness) in heterotopic bone formation induced by $\mathrm{CaP}$ ceramics could be clearly seen in this study with the well-designed materials. In fact, previous studies already showed that osteoblast-like cells favor rougher surface to smooth surface in vitro. ${ }^{37-40}$ It also has been demonstrated that microscale roughness with a high density of nanoscale features were superior to microscale roughness also in promoting osteogenic induction of the human osteosarcoma cell line MG63, determined by increased osteocalcin, osteoprotegerin, and vascular endothelial growth factor. Moreover, $\mathrm{Hu}$ et al. examined the changes in hMSC proliferation and differentiation after growth on silk/tropoelastin materials with different content of human tropoelastin, together with different surface roughness and micro/nanoscale surface patterns. They found that higher surface roughness with micro/nanoscale surface patterns, and by increasing the content of human tropoelastin in the materials, enhanced the proliferation and osteogenic differentiation of hMSCs. ${ }^{36}$ In our study, the different methods used to prepare the materials resulted in different micro-pore size [Fig. 1(b)] and thus in different surface roughness [Fig. $1(\mathrm{e}-\mathrm{h})$ ]. The result herein showed a relationship between surface properties of materials and bone induction in vivo. Many biochemists and biologists induce osteogenic differentiation of cells by topography factors in vitro, but there is no well-understood way of controlling such factors in vivo. We demonstrated in this report a clear mechanism for osteoinduction based on the surface architecture providing an explanation for the control of bone induction by specific surface roughness. It is most probable that surface architecture could physically affect osteogenic differentiation of stem cells or undifferentiated inducible osteoprogenitor cells in ectopic sites and lead to the new heterotopic bone formation.

How the surface architecture of CaP ceramics drives osteogenesis in ectopic sites is not clear as yet. It should be mentioned that, upon injury due to the surgery, an inflammatory reaction is immediately triggered to limit the damage while blood vessels restrict to stop bleeding. During this stage, macrophage migration to the injured site and quick formation of fibrin-based platelet-rich clot may have happened. ${ }^{56,57}$ Macrophages and platelets, together with endothelial cells in the damaged vessels, might have released various biomolecules (e.g., cytokines and several growth factors) prompting angiogenesis and migration of (stem) cells to the site. ${ }^{56,57}$ In this study, the presence of the microstructured surface of BCP implants may have driven such (stem) cells towards osteogenic differentiation favoring the observed ectopic bone formation. To confirm this suggestive mechanism, a histological analysis of short-term implants, that is within few days from implantation, is recommended to analyze the blood clot formation and presence of inflammatory cells in future studies.

Recently it has been shown that scaffolds seeded with human mesenchymal progenitor cells and enriched with rhBMP-7 could ectopically form bone tissue that resembled the typical characteristics of a physiological bone, including a trabecular structure surrounded by a cortex-like layer. ${ }^{58}$ We could not unequivocally identify the fat-like tissue present in the large channels of BCP-R [Fig. 4(d)] as fat marrow and therefore it is not possible to claim that the observed bone can be considered as a complete organ bone in the current study. However, the use of histochemical stains is 
suggested in future studies to identify the possible presence of bone marrow and better understand if material-driven ectopic bone formation can lead to a complete functional bone tissue.

The optimized CaP ceramics allowed us to study whether the surface architecture of $\mathrm{CaP}$ ceramics could act as a cue for osteoinduction of $\mathrm{CaP}$ ceramics in vivo. Although we have not pinpointed a mechanism where surface architecture triggers ectopic bone formation of $\mathrm{CaP}$ ceramics, to the best of our knowledge it is the first work describing the significant role of a surface architecture in bone formation in vivo, instead of in vitro osteogenic differentiation of stem cells driven by surface characteristics as often documented in literature.

\section{CONCLUSION}

Given the same chemical composition, surface area per volume, proteins adsorption, ion release rate, and surface mineralization ability, the surface architecture (i.e., surface roughness) affects bone forming ability of biphasic CaP ceramics, with a surface roughness of $\mathrm{Ra} 325.4 \pm 58.9 \mathrm{~nm}$ as a favorite scale for bone formation in this study. The results also showed that the percentage of bone volume in the channels was significantly affected by the surface architecture of the ceramics instead of the type (i.e., crossing vs. noncrossing) and size of the channels. Although the biological mechanism of ectopic osteogenesis of microporous CaP ceramics is far beyond understood, the current results demonstrate the surface roughness a cue for material-induced bone formation.

\section{REFERENCES}

1. Kanzler B, Kuschert SJ, Liu YH, Mallo M. Hoxa-2 restricts the chondrogenic domain and inhibits bone formation during development of the branchial area. Development 1998;125:2587-2597.

2. Gorski J. Is all bone the same? Distinctive distributions and properties of non-collagenous matrix proteins in lamellar vs. woven bone imply the existence of different underlying osteogenic mechanisms. Crit Rev Oral Biol Med 1998;9:201-223.

3. Van der Stok J, van Lieshout EM, El-Massoudi Y, van Kralingen $\mathrm{GH}$, Patka P. Bone substitutes in the Netherlands-A systematic literature review. Acta Biomater 2011;7:739-750.

4. Ripamonti U. Osteoinduction in porous hydroxyapatite implanted in heterotopic sites of different animal models. Biomaterials 1998; 17:31-35.

5. Yang Z, Yuan H, Tong W, Zou P, Chen W, Zhang X. Osteogenesis in extraskeletally implanted porous calcium phosphate ceramics: Variability among different kinds of animals. Biomaterials 1996; 17:2131-2137.

6. Yuan H, Kurashina K, de Bruijn JD, Li Y, de Groot K, Zhang X. A preliminary study on osteoinduction of two kinds of calcium phosphate ceramics. Biomaterials 1999;20:1799-1806.

7. Siddappa R, Martens A, Doorn J, Leusink A, Olivo C, Licht R, van Rijn L, Gaspar C, Fodde R, Janssen F, van Blitterswijk CA, de Boer J. cAMP/PKA pathway activation in human mesenchymal stem cells in vitro results in robust bone formation in vivo. Proc Natl Acad Sci U S A 2008;105:7281-7286.

8. Yamasaki H, Sakai H. Osteogenic response to porous hydroxyapatite ceramics under the skin of dogs. Biomaterials 1992;13:308312.

9. Klein C, de Groot K, Chen W, Li Y, Zhang X. Osseous substance formation induced in porous calcium phosphate ceramics in soft tissues. Biomaterials 1994;15:31-34.
10. Ripamonti $U$. The morphogenesis of bone in replicas of porous hydroxyapatite obtained from conversion of calcium carbonate exoskeletons of coral. J Bone Joint Surg Am 1991;73:692-703.

11. Ripamonti U, Richter PW, Thomas ME. Self-inducing shape memory geometric cues embedded within smart hydroxyapatite-based biomimetic matrices. Plast Reconstr Surg 2007;120:1796-1807.

12. Ripamonti $U$, Crooks $J$, Khoali $L$, Roden $L$. The induction of bone formation by coral-derived calcium carbonate/hydroxyapatite constructs. Biomaterials 2009;30:1428-1439.

13. Yuan $H$, van Blitterswijk CA, de Groot K, de Bruijn JD. Cross-species comparison of ectopic bone formation in biphasic calcium phosphate (BCP) and hydroxyapatite (HA) scaffolds. Tissue Eng 2006;12:1607-1615.

14. Gosain AK, Song L, Riordan P, Amarante MT, Nagy PG, Wilson CR, Toth JM, Ricci JL. A 1-year study of osteoinduction in hydroxyapatite-derived biomaterials in an adult sheep model. I. Plast Reconstr Surg 2002;109:619-630.

15. Habibovic $P$, Yuan $H$, van der Valk $C M$, Meijer $G$, van Blitterswijk CA, de Groot K. 3D microenvironment as essential element for osteoinduction by biomaterials. Biomaterials 2005;26:3565-3575.

16. Habibovic $P$, Sees TM, van den Doel MA, van Blitterswijk CA, de Groot K. Osteoinduction by biomaterials-Physicochemical and structural influences. J Biomed Mater Res A 2006;77:747-762.

17. Yuan H, Yang Z, Li Y, Zhang X, de Bruijn JD, de Groot K. Osteoinduction by calcium phosphate biomaterials. J Mater Sci Mater Med 1998;9:723-726.

18. Yuan H, Yang Z, de Bruijn JD, de Groot K, Zhang X. Materialdependent bone induction by calcium phosphate ceramics: A 2.5year study in dog. Biomaterials 2001;22:2617-2623.

19. Yuan H, de Bruijn JD, Li Y, Feng J, Yang Z, de Groot K, Zhang X. Bone formation induced by calcium phosphate ceramics in soft tissue of dogs: A comparative study between porous $\alpha$-TCP and $\beta$-TCP. J Mater Sci Mater Med 2001;12:7-13.

20. Kondo N, Ogose A, Tokunaga K, Umezu H, Arai K, Kudo N, Hoshino $M$, Inoue $H$, Irie $H$, Kuroda K, Mera H, Endo N. Osteoinduction with highly purified $\beta$-tricalcium phosphate in dog dorsal muscles and the proliferation of osteoclasts before heterotopic bone formation. Biomaterials 2006;27:4419-4427.

21. Yuan $H$, Fernandes $H$, Habibovic $P$, de Boer J, Barradas $A$, de Ruiter A, Walsh WR, van Blitterswijk CA, de Bruijn JD. Osteoinductive ceramics as a synthetic alternative to autologous bone grafting. Proc Natl Acad Sci U S A 2010;107:13614-13619.

22. Yuan H, van Blitterswijk CA, de Groot K, de Bruijn JD. A comparison of bone formation in biphasic calcium phosphate (BCP) and hydroxyapatite (HA) implanted in muscle and bone of dogs at different time periods. J Biomed Mater Res A 2006;78:139-147.

23. Ie Nihouannen D, Saffarzadeh A, Gauthier O, Moreau F, Pilet P, Spaethe R, Layrolle P, Daculsi G. Bone tissue formation in sheep muscles induced by a biphasic calcium phosphate ceramic and fibrin glue composite. J Mater Sci Mater Med 2008;19:667-675.

24. Yuan H, van den Doel M, Li S, van Blitterswijk CA, de Groot K, de Bruijn JD. A comparison of the osteoinductive potential of two calcium phosphate ceramics implanted intramuscularly in goats. J Mater Sci Mater Med 2002;13:1271-1275.

25. Habibovic $P$, van der Valk C, van Blitterswijk CA, de Groot K Meijer G. Influence of octacalcium phosphate coating on osteoinductive properties of biomaterials. J Mater Sci Mater Med 2004; 15:373-380.

26. Li JP, Habibovic $P$, Yuan $H$, van den Doel $M$, Wilson CE, de Wijn $J R$, van Blitterswijk CA, de Groot K. Biological performance in goats of a porous titanium alloy-biphasic calcium phosphate composite. Biomaterials 2007;28:4209-4218.

27. Habibovic P, Kruyt MC, Juhl MV, Clyens S, Martinetti R, Dolcini L, Theilgaard N, van Blitterswijk CA. Comparative in vivo study of six hydroxyapatite-based bone graft substitutes. J Orth Res 2008; 26:1363-1370.

28. Kurashina K, Kurita H, Wu Q, Ohtsuka A, Kobayashi H. Ectopic osteogenesis with biphasic ceramics of hydroxyapatite and tricalcium phosphate in rabbits. Biomaterials 2002;23:407-412.

29. Habibovic $P$, Yuan $H$, van den Doel $M$, Sees TM, van Blitterswijk CA, de Groot K. Relevance of osteoinductive biomaterials in critical-sized orthotopic defect. J Orth Res 2006;24:867-876. 
30. Ripamonti U, Crooks J, Tucker M, Sampath T, Rueger D, Reddi A. Long-term evaluation of bone formation by osteogenic protein 1 in the baboon and relative efficacy of bone-derived bone morphogenetic proteins delivered by irradiated xenogeneic collagenous matrices. J Bone Min Res 2000;15:1798-1809.

31. Duneas N, Crooks J, Ripamonti U. Transforming growth factor- $\beta$ 1: Induction of bone morphogenetic protein genes expression during endochondral bone formation in the baboon, and synergistic interaction with osteogenic protein-1 (BMP-7). Growth Factors 1998; 15:259-277.

32. Ripamonti $U$, Heliotis $M$, Rueger D, Sampath $T$. Induction of cementogenesis by recombinant human osteogenic protein-1 (hOP-1/BMP-7) in the baboon (Papio ursinus). Arch Oral Biol 1996;41:121-126.

33. Barradas A, Fernandes HA, Groen N, Chai YC, Schrooten J, van de Peppel J, van Leeuwen JP, van Blitterswijk CA, de Boer J. A calcium-induced signaling cascade leading to osteogenic differentiation of human bone marrow-derived mesenchymal stromal cells. Biomaterials 2012;33:3205-3215.

34. Geesink R, de Groot K, Klein C. Bonding of bone to apatite-coated implants. J Bone Joint Surg Br 1988;70:17-22.

35. Fujibayashi S, Neo M, Kim HM, Kokubo T, Nakamura T. Osteoinduction of porous bioactive titanium metal. Biomaterials 2004;25: 443-450.

36. Hu X, Park SH, Gil ES, Xia XX, Weiss AS, Kaplan DL. The influence of elasticity and surface roughness on myogenic and osteogenic-differentiation of cells on silk-elastin biomaterials. Biomaterials 2011;32:8979-8989.

37. Anselme K, Bigerelle M. Topography effects of pure titanium substrates on human osteoblast long-term adhesion. Acta Biomater 2005;1:211-222.

38. Bowers KT, Keller JC, Randolph BA, Wick DG, Michaels CM. Optimization of surface micromorphology for enhanced osteoblast responses in vitro. Int J Oral Maxillofac Implants 1992;7:302-310.

39. Kommireddy DS, Sriram SM, Lvov YM, Mills DK. Stem cell attachment to layer-by-layer assembled $\mathrm{TiO}_{2}$ nanoparticle thin films. Biomaterials 2006;27:4296-4303.

40. Zhao G, Raines A, Wieland M, Schwartz Z, Boyan B. Requirement for both micron-and submicron scale structure for synergistic responses of osteoblasts to substrate surface energy and topography. Biomaterials 2007;28:2821-2829.

41. Mendonca G, Mendonca D, Simoes LGP, Araujo AL, Leite ER, Duarte WR, Aragao FJ, Cooper LF. The effects of implant surface nanoscale features on osteoblast-specific gene expression. Biomaterials 2009;30:4053-4062.

42. Oh S, Brammer KS, Li Y, Teng D, Engler AJ, Chien S, Jin S. Stem cell fate dictated solely by altered nanotube dimension. Proc Natl Acad Sci U S A 2009;106:2130-2135.

43. Dalby MJ, McCloy D, Robertson M, Agheli H, Sutherland D, Affrossman S, Oreffo RO. Osteoprogenitor response to semi- ordered and random nanotopographies. Biomaterials 2006;27: 2980-2987.

44. Kilian KA, Bugarija B, Lahn BT, Mrksich M. Geometric cues for directing the differentiation of mesenchymal stem cells. Proc Natl Acad Sci U S A 2010;107:4872-4877.

45. Dalby MJ, Gadegaard N, Tare R, Andar A, Riehle MO, Herzyk P, Wilkinson CD, Oreffo RO. The control of human mesenchymal cell differentiation using nanoscale symmetry and disorder. Nature Mater 2007;6:997-1003.

46. Fu J, Wang YK, Yang MT, Desai RA, Yu X, Liu Z, Chen CS. Mechanical regulation of cell function with geometrically modulated elastomeric substrates. Nat Methods 2010;7:733-736.

47. Kokubo T, Takadama H. How useful is SBF in predicting in vivo bone bioactivity? Biomaterials 2006;27:2907-2915.

48. Barradas AMC, Yuan H, van Blitterswijk CA, Habibovic P. Osteoinductive biomaterials: Current knowledge of properties, experimental models and biological mechanisms. Eur Cell Mater 2011; 21:407-429.

49. Curtis A, Wilkinson C. Nantotechniques and approaches in biotechnology. Trends Biotechnol 2001;19:97-101.

50. Galli C, Piemontese M, Lumetti S, Manfredi E, Macaluso G, Passeri G. The importance of WNT pathways for bone metabolism and their regulation by implant topography. Eur Cells Mater 2012;24:46-59.

51. Chai YC, Truscello S, van Bael S, Luyten FP, Vleugels J, Schrooten J. Perfusion electrodeposition of calcium phosphate on additive manufactured titanium scaffolds for bone engineering. Acta Biomater 2011;7: 2310-2319.

52. Winter GD, Simpson BJ. Heterotopic bone formation in a synthetic sponge in the skin of young pigs. Nature 1969;223:88-90.

53. Barbieri D, Renard AJS, de Bruijn JD, Yuan H. Heterotopic bone formation by nano-apatite containing poly(D,L-lactide) composites. Eur Cells Mater 2010;19:252-261.

54. Arafat MT, Lam CXF, Ekaputra AK, Wong SY, Li X, Gibson I. Biomimetic composite coating on rapid prototyped scaffolds for bone tissue engineering. Acta Biomater 2011;7:809-820.

55. Vaquette C, Ivanovski S, Hamlet SM, Hutmacher DW. Effect of culture conditions and calcium phosphate coating on ectopic bone formation. Biomaterials 2013;34:5538-5551.

56. Anderson JM, Rodriguez A, Chang DT. Foreign body reaction to biomaterials. Semin Immunol 2008;20:86-100.

57. Davies JE. Understanding peri-implant endosseous healing. J Dent Ed 2003;67:932-949.

58. Holzapfel BM, Wagner F, Loessner D, Holzapfel NP, Thibaudeau L, Crawford R, Ling MT, Clements JA, Russell PJ, Hutmacher DW. Species-specific homing mechanisms of human prostate cancer metastasis in tissue engineered bone. Biomaterials 2014;35:41084115. 